\title{
Material tests of 316L austenitic stainless-clad steel at elevated temperatures
}

\author{
R. S. Bai ${ }^{\mathrm{a}}$, H. Y. Ban ${ }^{\mathrm{b} *}$, K. F. Chung ${ }^{\mathrm{c}}$ and Yin Bai ${ }^{\mathrm{a}}$ \\ aShool of Transportation Science and Engineering, Beihang University, China \\ ${ }^{b}$ Key Laboratory of Civil Engineering Safety and Durability of China Education Ministry, Department of Civil \\ Engineering, Tsinghua University, China \\ ${ }^{\mathrm{c}}$ Department of Civil and Environmental Engineering, The Hong Kong Polytechnic University, Hong Kong, \\ China \\ *corresponding author, e-mail address: banhy@tsinghua.edu.cn
}

\begin{abstract}
Mechanical properties of stainless-clad (SC) steel plates at elevated temperatures are key parameters for fire resistant design and numerical simulation analysis of SC steel structures. Compared with pure stainless steel and pure ordinary steel, SC steel not only combines advantages of the two component metals, but may also balance the performance and cost; however, it behaves quite differently in terms of material properties. In order to quantify this performance, tension coupon tests at room as well as elevated temperatures are conducted on the SC steel plate. Based on the test results, failure modes of the tension coupons are analysed, and full-range stress-strain curves are obtained; material properties are accordingly determined and described herein, and analyses are performed on several properties including yield strength, ultimate tensile stress, elastic modulus and elongation after fracture. It is found that with an increase of the temperature, both the elastic modulus and strengths are reduced remarkably. For determining these material properties quantitatively and developing robust constitutive models of the SC steel at elevated temperatures, more test data are needed, and the incorporation of the effects of the clad ratio on the material properties at both room and elevated temperatures is also necessary. The present research outcomes may provide valuable reference for fire design and calculations of the SC steel.
\end{abstract}

Keywords: Stainless-clad steel; elevated temperatures; mechanical properties; experiment.

\section{Introduction}

SC steel is an advanced high-performance composite steel [1] with stainless-clad steel and ordinary steel being bonded together by hot rollbonding process [2], which has their own advantages of both stainless steel [3] and ordinary one, including low production costs, corrosion resistant and meeting the demand of strength [4]. SC steel has been applied in engineering structures as building curtain wall and bridge decks, with great potential to replace the engineering application of stainless steel in tubular structural elements [1]. The design and analysis methods of building structures under room temperature are relatively mature, but building fires occur frequently, so the safety of building structures under fire is facing unprecedented challenges [5]. Due to less research of SC steel's mechanical properties, especially that at elevated temperatures, the engineering application is mainly limited in chemical industry, pressure vessels and ship industry etc. [6], whilst for the use in the construction industry, that performance needs to be clarified [7].

Currently, there seems no reports on the properties of SC steel at elevated temperatures, but some relevant research has been carried out on the stainless steel or ordinary steel separately, such as that by Outinen [8], Sakumoto et al. [9], Chen and Yong [10], Abdella [11], Zhao [12], 
Montanari and Zilli [13], Willam [14], Gardner et al. [15] or Zhao and Shen [16].

In this paper, based on the method of steady state at elevated temperature, tests of $316 \mathrm{~L}$ austenitic stainless-clad steel at various temperatures were conducted on the mechanical properties. The reduction factors of initial elasticity modulus, yield strength and ultimate strength at different temperatures were presented. The research outcomes may provide a scientific base for development of constitutive relationship of the SC steel plate.

\section{Experimental program}

\subsection{Test at room temperature}

The SC steel plates tested in this study were fabricated through hot-rolling process [17] by using 316L austenitic stainless steel as the clad material (3 mm thick) and Q235B steel as the base one ( $5 \mathrm{~mm}$ thick). Size of the specimen for tension coupon is shown in Figs. 1 and 2. A total of 3 tension coupons were designed and prepared. For instance, specimen TC-20-1 represents a tension coupon at $20{ }^{\circ} \mathrm{C}$, the second number denotes the serial one for a group. Table 1 gives measure size of tension coupons at room temperature.

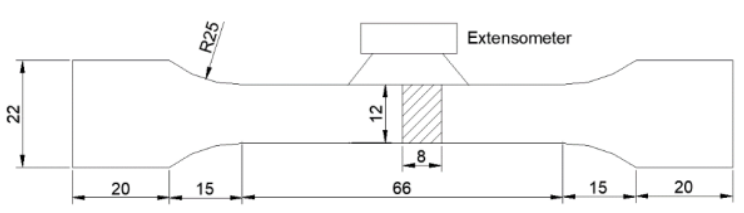

Fig. 1. Geometry of specimens at room temperature.

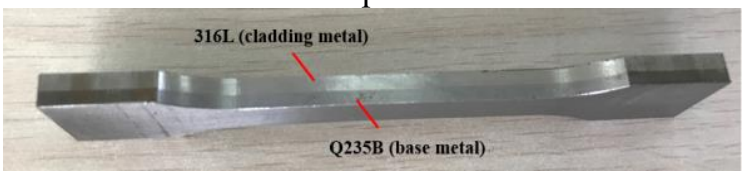

Fig. 2. Photo of specimen at room temperature.

Table 1.Geometric measurements of the specimens at room temperature.

\begin{tabular}{ccccc}
\hline Specimens & $\beta_{\mathrm{N}}$ & $t_{\mathrm{c}}(\mathrm{mm})$ & $t(\mathrm{~mm})$ & $\beta_{\mathrm{M}}$ \\
\hline TC-20-1 & 0.38 & 3.28 & 8.16 & 0.42 \\
TC-20-2 & 0.38 & 3.29 & 8.22 & 0.40 \\
TC-20-3 & 0.38 & 3.03 & 8.18 & 0.37 \\
\hline
\end{tabular}

Note: $\beta_{\mathrm{N}}$ means the nominal value of clad ratio of the specimens; $t_{\mathrm{c}}$ means the thickness of the cladding metal; $t$ means the total thickness of the specimens; $\beta_{\mathrm{M}}$ means the calculated clad ratio using measurements.
Standard tension coupon tests were carried out according to GB/T 228.1-2010 [18]. A Zwick universal materials tester, type Z100, $100 \mathrm{kN}$ as shown in Fig. 3(a) was utilized and the measurement of strain is shown in Fig. 3(b). The test uses automatic stress-control loading, and the stress rate is controlled at $6 \sim 60 \mathrm{~N} / \mathrm{s}$ before yielding, then the test rate is increased to a strain rate of no more than $0.008 \mathrm{~s}^{-1}$ after yielding. The strain was measured using a contact extensometer, of which a gauge length of $55 \mathrm{~mm}$ was set. The extensometer can track the strain readings until final fracture failure of the coupon.

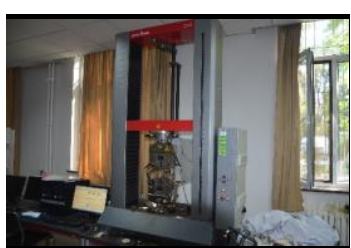

(a) Test device

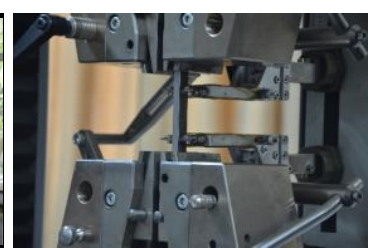

(b) Measurement of strain
Fig. 3. Test setup at room temperature.

\subsection{Test at elevated temperatures}

The same SC steel plate was used with the above test. Size of the specimen for tension coupon tests at elevated temperatures is shown in Fig. 4. A total of 10 tension coupons were designed and prepared herein, and the temperatures are $200^{\circ} \mathrm{C}, 400^{\circ} \mathrm{C}, 600^{\circ} \mathrm{C}, 800^{\circ} \mathrm{C}$, $900^{\circ} \mathrm{C}$. Two specimens at each elevated temperature were prepared and their labeling rules are the same as above.

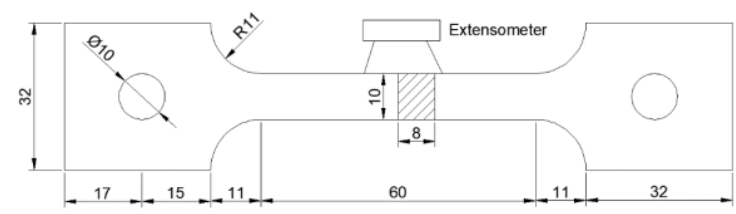

Fig. 4. Geometry of specimens at elevated temperatures.

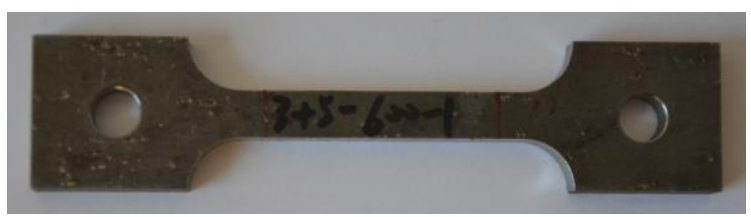

Fig. 5. Photo of one specimen for tests at elevated temperature. 
Table 2. Geometric measurements of the specimens at elevated temperatures.

\begin{tabular}{ccccc}
\hline Specimens & $\beta_{\mathrm{N}}$ & $t_{\mathrm{c}}(\mathrm{mm})$ & $t(\mathrm{~mm})$ & $\beta_{\mathrm{M}}$ \\
\hline TC-200-1 & 0.38 & 3.25 & 8.17 & 0.40 \\
TC-200-2 & 0.38 & 3.22 & 8.19 & 0.39 \\
TC-400-1 & 0.38 & 3.25 & 8.15 & 0.40 \\
TC-400-2 & 0.38 & 3.24 & 8.26 & 0.39 \\
TC-600-1 & 0.38 & 3.25 & 8.12 & 0.40 \\
TC-600-2 & 0.38 & 3.14 & 8.10 & 0.39 \\
TC-800-1 & 0.38 & 3.29 & 8.17 & 0.40 \\
TC-800-2 & 0.38 & 3.19 & 8.13 & 0.39 \\
TC-900-1 & 0.38 & 3.31 & 8.18 & 0.40 \\
TC-900-2 & 0.38 & 3.21 & 8.13 & 0.39 \\
\hline
\end{tabular}

Standard tension coupon tests were carried out according to GB/T 228.2-2010 [19]. A MTS universal materials tester, type MTS880, $100 \mathrm{kN}$ as shown in Fig. 6 was utilized and a heating equipment was MTS653, up to $1200{ }^{\circ} \mathrm{C}$. The test uses automatic strain-control loading, and the strain rate is controlled at $0.3 \mathrm{~mm} / \mathrm{min}$ before yielding, then the test rate is increased to 5 $\mathrm{mm} / \mathrm{min}$. The strain was measured using an elevated temperature extensometer, type MTS632.53F, of which a gauge length of $25 \mathrm{~mm}$ was set.

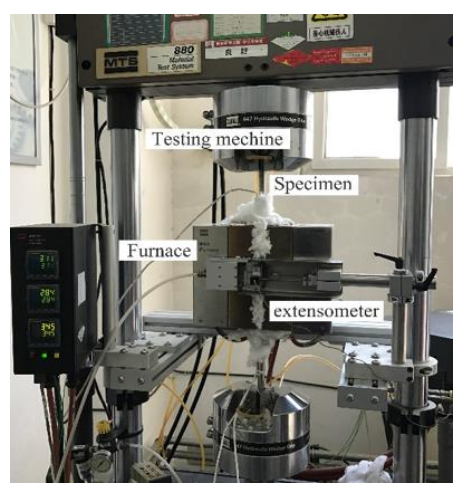

Fig. 6. Test setup at elevated temperatures.

\section{Test Results and Analyses}

\subsection{Failure modes}

With respect to the tests at room temperature, at the beginning of the application of tension load, no significant plastic deformation occurred. After reaching the ultimate tensile strength, a conspicuous necking phenomenon can be observed. With development of necking, the specimens suddenly separated from each other within the necking area, followed by eventual fracture. Photos of fracture failure are shown in Fig. 7.

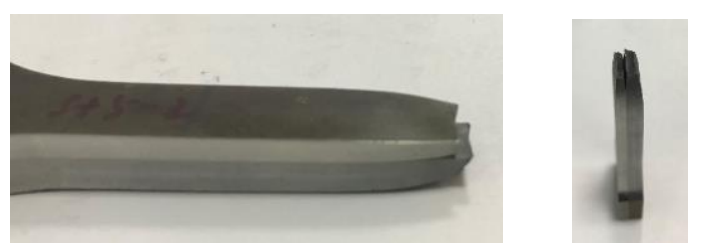

$\begin{array}{ll}\text { (a) Specimen fracture } & \text { (b) Separated layer }\end{array}$

Fig. 7. Fracture failure of specimens at room temperature.

With respect to the tests at elevated temperatures, failure phenomenon of tensile specimens is shown in Fig. 8. Each specimen experienced visible plastic deformation from stretching to breaking, with marked necking being observed. It's noteworthy that, the plastic deformation of Q235B steel is larger than that of 316L austenitic steel, i.e. the stainless steel component fractured first at elevated temperatures. It shows that the clad steel's ductility has been worsened compared with the base steel at elevated temperatures.

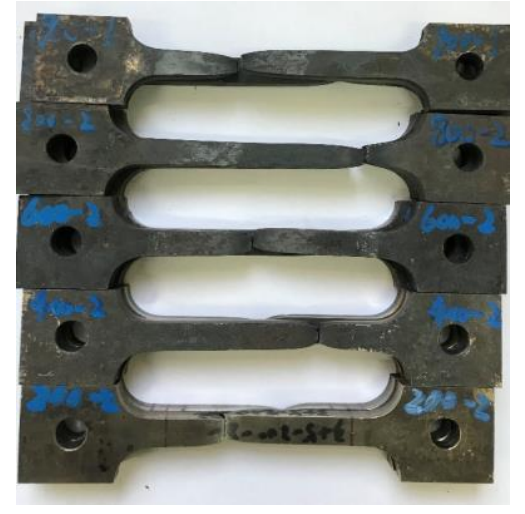

Fig. 8. Failure modes of coupons at elevated temperatures.

\subsection{Stress-strain curves}

Figs. 9(a) (f) show stress-strain curves of each group of tension coupons. It should note that curves appears different in terms of initial modulus in Figs. 9(c) (e). As can be seen that when the temperatures is lower than $600^{\circ} \mathrm{C}$, the curves are smooth, but fluctuating in case the temperature is higher than $600^{\circ} \mathrm{C}$. It can be seen that the slope of the curve, with an increase of the temperatures, is getting smaller, and the peak point is also smaller. These phenomena are due to descending properties of the two kinds of materials at elevated temperatures. The effect of this temperature on the individual tensile properties of the SC steel will be discussed further. 


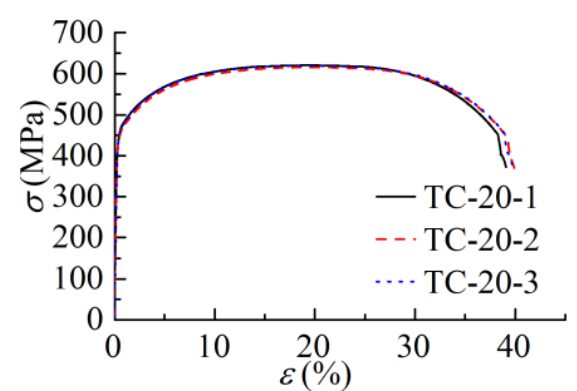

(a)

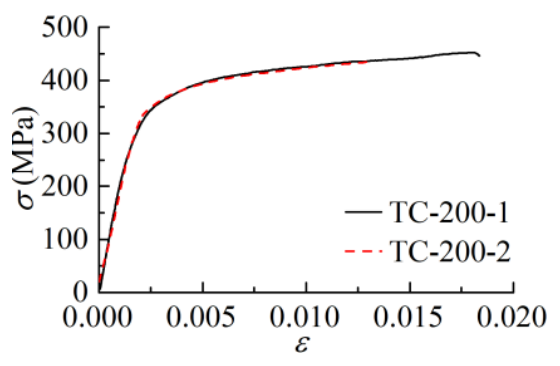

(b)

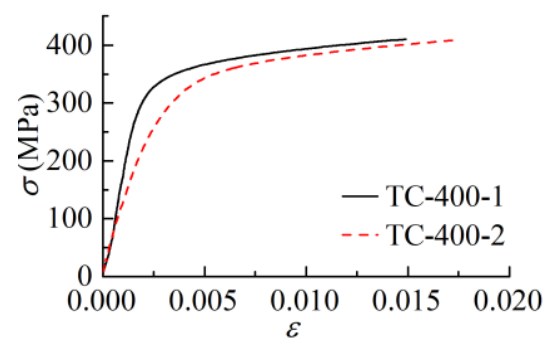

(c)

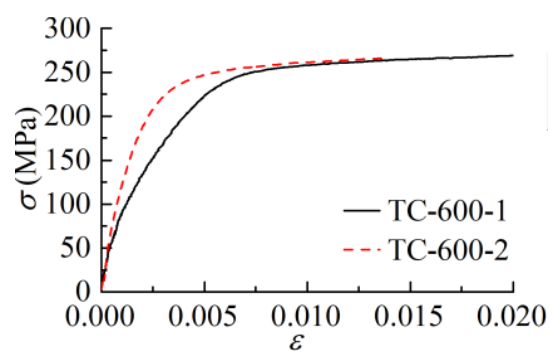

(d)

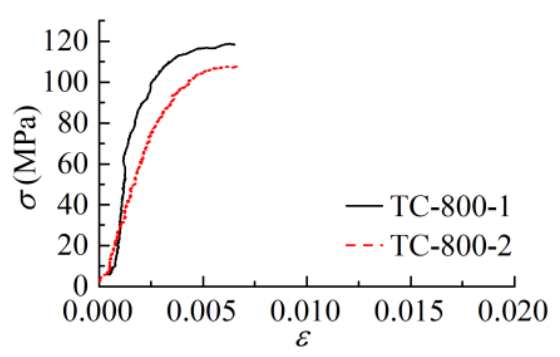

(e)

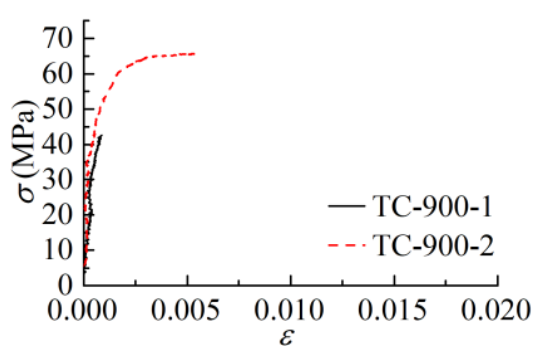

(f)

Fig. 9. Stress-strain curves of SC steel at various temperatures

\subsection{Material properties}

Based on the test results, it can be found that elastic modulus of the SC steel decreases with the temperatures being increased generally, this is because of the elasticity modulus of cladding steel and base steel both being reduced with increasing temperature, and the base steel weakened more severely. Similarly, the yield strength decreases with the temperature increasing, as shown in Fig. 10. And the tensile strength is also in the same case, as shown in Fig. 11. At the room temperature, the two component steels fractured at the same time, whilst at other elevated temperatures the specimens have two different elongation percentages after fracture for the two layers.

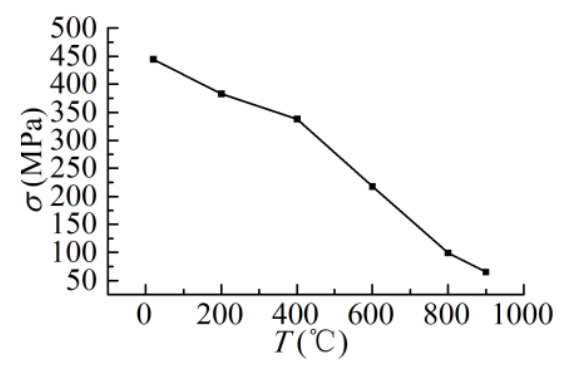

Fig. 10. Relationship between $\sigma_{0.2}$ and $T$

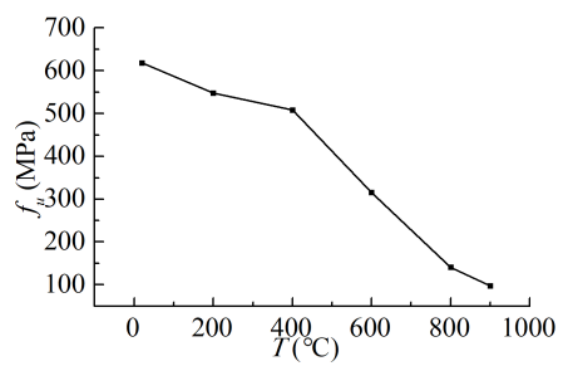

Fig. 11. Relationship between $f_{\mathrm{u}}$ and $T$ 


\section{Conclusions}

In this paper, primary standard tension coupon tests of SC steel are carried out. A number of test data are obtained and various material properties with temperature varying are clarified. The following conclusions may be made:

(1) SC steel is a typical non-liner material with no visible yield plateau generally, of which yield strength is determined by the proof strength corresponding to $0.2 \%$ plastic strain.

(2) The temperature has significant effects on the elastic modulus, yield strength, ultimate tensile stress and elongation percentage. It is necessary to put forward a constitutive relationship with temperatures varying.

(3) Two component materials are inconsistent with elastic modulus and elongation percentage at elevated temperatures.

\section{Acknowledgements}

This work was financially supported by the National Natural Science Foundation of China (Nos. 51608300, 51778329), which are gratefully acknowledged.

\section{References}

[1] Ban HY, Shi YJ, Tao XY. Use of Clad Steel in Engineering Structures. EASEC-15 2017;11671173.

[2] Na SS, Tao JZ. Application of rolling industry in metal composite panel. The Proceedings of Hebei Province's Rolling Steel Technology and Academic Annual Meeting 2007;31-33.

[3] Wang YQ, Yuan HX, Shi YJ, Gao B, Dai GX. A review of current applications and research of stainless steel structure. Steel Construction 2010;25(2):1-13. (in Chinese)

[4] Bai RS, Ban HY, Shi YJ, Bai Y. Material Tests of Titanium Clad Steel Plate. 9th International Symposium on Steel Structures 2017; 697-700.

[5] Fan SG, Sun WJ, Gui HY. Fire resistance performance analysis of $\mathrm{H}$-section stainless steel column under axial compression. Engineering Mechanics 2016;33(6):154-162. (in Chinese)

[6] Motarjemi KA, Kocak M, Ventzke V. Mechanical and fracture characterization of a bimaterial steel plate. International Journal of Vessels and Piping 2002; 79:181-191.
[7] Baddoo NR. Stainless steel in construction: A review of research, applications, challenges and opportunities. Journal of Constructional Steel Research 2008; 64:1199-1206.

[8] Ala-Outinen T. Fire Resistance of austenitic stainless steels Polarit 725 (EN1.4301) and Polarit 761 (EN1.4571). Espoo (Finland): VTT research nots $1760 ; 1996$.

[9] Sakumoto BY, Nakazato T, Matsuzaki A. Hightemperature properties of stainless steel for building structures. Journal of Constructional Engineering 1996;12(4):399-406.

[10]Chen J, Young B. Stress-strain curves for stainless steel at elevated temperatures. Engineering Structures 2006;28(2):229-239. (in Chinese)

[11] Abdella K. Explicit full-range stress-strain relations for stainless steel at high temperatures. Journal of Constructional Steel Research 2009;65(4):794-800.

[12]Zhao B. Material behaviour at elevated temperatures. CTICM, France: Work package 5.1: ECSC project 'Development of use of stainless steel in construction' 2000.

[13] Montanari A, Zilli G. Properties at elevated temperatures. CSM, Italy: Work package 4: RFCS Project 'Stainless Steel in Fire' 2007.

[14] Willam KJ, Warnke EP. Constitutive models for the triaxial behaviour of concrete. Proceedings of International Association for Bridge \& Structural Engineering-Concrete Structures Subjected to Triaxial Stresses 1975:1-30.

[15] Gardner L, Insausti A, Ng KT. Elevated temperature material properties of stainless steel alloys. Journal of Constructional Steel Research 2010;66(5):634-647.

[16]Zhao JC, Shen ZY. Material property model in the analysis of fire resistance of steel structures. Industrial Construction 1996;26(9):3-8. (in Chinese)

[17] Smith L. Engineering with Clad Steel (2nd Edition). Nickel Institute Technical Series N0 2012; 10064:1-24.

[18]GB. GB/T 228.1-2010 Metallic materialsTensile testing-Part 1: Method of test at room temperature 2010. (in Chinese)

[19]GB. GB/T 228.2-2015 Metallic materialsTensile testing-Part 2: Method of test at elevated temperature 2015. (in Chinese) 